\title{
RESEARCH PAPER ON BELL CURVE METHOD OF PERFORMANCE MANAGEMENT
}

\author{
Dr. Tejashree Deshmukh \\ Dean-Academics, PTVA's Institute of Management \\ Vile Parle (East), Mumbai, India \\ Jigar Patel \\ Assistant Professor - HR, PTVA's Institute of Management \\ Vile Parle (East), Mumbai, India
}

\begin{abstract}
The most important competitive advantage any organization can have, is it's human capital. The organizations that know how to recruit, deploy, develop and retain this most valued asset, will succeed in this world. Performance Management System is one such tool that plays a crucial role in assessing, developing and retaining of the employees. Todays' organization need to think of Performance Appraisal System that assesses the performance of employees objectively, motivates them to perform better, allows them to develop required knowledge, skills and abilities and most importantly helps the organizations retain the high performers. This paper aims to study Bell Curve Method of Performance Appraisal which is widely used for this purpose, and any alternatives that can help the organizations assess its employees better, thereby helping them develop and retain the high performers.
\end{abstract}

Keywords: Performance Appraisal, Performance Management System (PMS), Bell Curve.

Cite this Article: Dr. Tejashree Deshmukh and Jigar Patel, Research Paper on Bell Curve Method of Performance Management, International Journal of Management, 10 (1), 2019, pp. 38-42.

http://iaeme.com/Home/issue/IJM?Volume=10\&Issue=1

\section{BELL CURVE METHOD OF PERFORMANCE MANAGEMENT}

The term "Performance Management" was first introduced by Michael Beer as an innovative appraisal and development system. It was introduced as an improvement over the more subjective, traditional performance appraisal system which was plagued by rater problems. Performance Management System (PMS) is a comprehensive, integrated, business driven system aimed at organizational and people development.

\section{WHAT IS PERFORMANCE MANAGEMENT SYSTEM (PMS)}

Performance Management System is the process of Performance Planning (goal setting), Performance Monitoring and Coaching, Measuring (evaluating) Individual Performance 
linked to organizational goals, giving him/her feedback, rewarding the individual based on his/her achievements against set performance goals and required competencies, and working out a plan for his/her development. (Sahu, 2007)

\section{BELL CURVE METHOD OF PMS}

Bell Curve Method of Performance Management is a Forced-distribution method where the rater is required to assign employees in the work group to a limited number of categories so as to approximate a normal frequency distribution. It was first introduced by Jack Welch of General Electric wherein a predetermined percentage of employees is placed in each performance category. The Bell Curve is a symmetric curve that is pronounced at the middle and tapered off at the edges. The Bell Curve method of Performance Management is based on the premise that in order to develop and thrive, the company must identify the best and the worst performers, and nurture the former and rehabilitate and/or discard the latter. It categorizes employees based on their performance and rewards or reprimands them accordingly. Under this system, the performance of the employees who are engaged in similar activities is compared and then the ranking is arrived at based on this performance. General norm followed for this classification is: $20 \%$ as High Performers, $70 \%$ as Average Performers and $10 \%$ as Non-Performers. However, there is no strict rule regarding this distribution.

\section{WHY BELL CURVE METHOD OF PMS}

\subsection{To recognize Top Performers}

It is very important for an organization to identify its high performers and reward them accordingly. The Bell Curve Method requires the managers to make decisions and differentiate between employees based on their performances. As high performers get rewarded, they feel motivated and work harder to grow in the company. This eventually leads to better career planning of these top performers and leads to better retention in the organization. This kind of approach also strengthens succession planning.

\subsection{To identify employee-job fit in an organization}

The performance of an employee can be identified with the help of Bell Curve methods. An adequate analysis of his/her performance with the help of proper HR interventions, can identify if this employee is really suitable for the current job or not. This approach may reveal other positions in the organization that may be more suited for the employee in the company. The forced distribution with required analysis and HR intervention, can identify other positions within the organization for employees. By keeping in mind their competencies, strengths and career plans viz-a-viz the current openings, HR can be instrumental in planning the employee development.

\subsection{Efficient \& effective allocation of Training to the employees}

Bell curve method of Performance Management helps in identifying the gaps in the desired performance and an actual performance which might be a result of lack of skill, knowledge or ability on part of the employee. After identifying the reason, an organization can correct the situation by providing necessary training to the employee to either acquire or upgrade the existing skill, knowledge and ability. If an employee is found to be unsuitable for the concerned job following Bell Curve Method of PMS, he/she can be reallocated to some other portfolio. 


\subsection{Minimize Rater's Errors}

Bell curve method of Performance Management helps in minimizing rater's errors commonly seen during the appraisal process. Error such as leniency or strictness as well as central tendency are minimized while using the Bell curve method as it requires the employees to be categorized in three groups.

\section{PROBLEMS ASSOCIATED WITH BELL CURVE METHOD OF PMS:}

\subsection{Forced Distribution of Employees}

Bell curve method forces the distribution of employees in three categories of High Performers, Average Performers and Non-performers. Many times, this does not represent the actual scenario. An organization may have more numbers of employees in any one category who need to be pushed in to some other category due to forced distribution required under Bell Curve Method.

\subsection{Employees Tend to Concentrate More on Visible Performance than the Required Performance}

As the visible performance of the employee gets noticed quickly by the management rather than the performance required, employees begin to concentrate their efforts on the performance which will be more noticeable and may not pay attention to such factors which might be very crucial to the success and effectiveness of the work done, but which may not be noticeable.

\subsection{Hampers Team Spirit in the Organization}

As a result of constant pressure for high performance, employees get, employees get very self-concerned. There develops a culture of distrust and misbelief. People hesitate helping the fellow employees fearing that they will get better rating and as a result of these, the team spirit in the organization suffers.

\subsection{Reduced Morale}

Employees are constantly under pressure for performance and are anxious about consequences in case their performance is not up to the mark. Tough job market adds to their anxiety and slowly this starts reducing their morale and affects their performance negatively.

\subsection{Not suitable for Smaller Organizations:}

In the organization with less than 300 employees, Bell Curve method may not work well because the categorization of employees into high performers, average performers and nonperformers in such cases may be erroneous.

\subsection{Increased Attrition}

As a result of high anxiety and low morale due to constant pressure of high performance and a fear that an employee can be shown a door at the slightest mistake, there is a possibility of attrition rate in the organization increasing with Bell Curve method.

\section{ALTERNATIVE TO BELL CURVE METHOD OF PMS IN TODAY'S CONTEXT}

Today, organizations have started realizing the limitations of Bell Curve Method of PMS which discourages the team spirit which plays a crucial role in the success of any company in 
current scenario. Such system breed unhealthy competition among employees and encourages political behavior in the organization.

Hence, instead of following Bell Curve Method of PMS which relies on normal distribution, a method following Power Law distribution, may yield better performance from the employees and hence, better results for the organization.

Power law distribution for performance means a very small percentage of employees contribute a disproportional amount of output. In 80/20 parlance, it means 80 percent of output comes from 20 percent of employees. Power law distribution is more relevant in $21 \mathrm{st}$ century organizations employing knowledge workers, whereas normal distribution was more suitable for the manufacturing era. (O'Boyle et al, 2012)

When an organization tries to force a normal distribution upon a power law distribution, it underestimates the work of high performer and overestimates the work of an average or low performer.

Rewards in the organization should be based on performance distribution. Simply speaking, salary differentials should reflect performance differentials. The difference in pay of an outstanding and an average performer even in today's companies, is only up to about 1.5 times most of the times. However, in some jobs like sales where variable compensation prevails and performance can be clearly measured in numbers, the situation is improving faster. Even today, only a handful of organizations have instituted salary differentials going up to $300 \%$ within the same job grade. Such organizations that follow a high salary differentiation policy have higher employee engagement.

The question is - Does individual performance follow a normal distribution or a power law distribution? Many times it is difficult to measure performance objectively, and subjective measures of performance are required to be used

It is primarily for HR practitioners to understand performance distribution for various positions within the company and plan various HR processes including performance management, compensation, career planning, learning \& development etc. accordingly.

Bell Curve method which does not address the issues off unfairness and inequity, cannot manage the transition from manufacturing economy to knowledge economy. It discourages collaboration and doesn't help in productivity. Today's organizations must practise a performance management system where the employees are assessed based on their work as well as on the basis of their team work. Also the important points to be kept in mind would be: does your organization follow a system of SMART objectives which makes it easier and more objective to decide the performance and is there consistency in the performance of the employee. An organization must have a feedback system as well as redressal system to address the issues and need of the employees.

\section{REFERENCES}

[1] Gary, L, For Whom the Bell Curve Tolls, Harvard Management Review, 2001

[2] Grote, R. C. and D. Grote, Forced ranking: making performance management work. , Harvard Business Review, 2005

[3] Dr. Twinkle Prusty, Predicting Corporate Governance On Performance Measures In Select Indian Corporates, International Journal of Advanced Research in Management (IJARM), Volume 5, Issue 4, July- August (2014), pp. 01-10

[4] O'Boyle, Ernest, Jr.; Aguinis, Herma, The Best and the Rest: Revisiting the Norm of Normality of Individual Performance, n, Personnel Psychology, v65, 2012,pp 79 - 119 


\section{Research Paper on Bell Curve Method of Performance Management}

[5] Dr. Bishawjit Chandra Deb, ArupaSarker and Fahimul Kader Siddique. Relationship between Corporate Governance and Financial Performance of Banking Industry in Bangladesh. Journal of Management, 4(2), 2017, pp. 50-61.

[6] Repenning, N. P. and J. D. Sterman "Nobody ever gets the credit for fixing problems that never happened: Creating and sustaining process improvement." California Management Review 43(4): 64.

[7] Wijaya, Some Considerations of the Actual Problems Related to Good Corporate Governance, and the Impetus for Law Enforcement. International Journal of Civil Engineering and Technology, 8(9), 2017, pp. 867-873

[8] Sahu,R.K Performance Management System. Excel Books, New Delhi, 2007

[9] Vaishnav C., Khakifirooz A., Devos M, Punishing by Rewards: When the Performance Bellcurve Stops Working for You, 2006.

[10] Use of Bell Curve in Performance Appraisals - Good or Bad? Extracted on February 8, 2019 fromhttps://www.peoplematters.in/article/performance-management/bell-curve-or-an-1curve-performance-management-once-again-14481 